\title{
Ability of the Mini-Mental State Examination to Predict the Neuropsychological Performance of Hispanic Patients with Minor Neurocognitive Disorder
}

\author{
Jorge A. Herrera Pino, ${ }^{1,2}$, Norella S. Jubiz Bassi ${ }^{3}$, Jose Armas ${ }^{1,2}$, Nora Dieguez ${ }^{1,3}$ \\ ${ }^{1}$ Medical Care Consortium, Inc. (MCCI), Miami, USA \\ ${ }^{2}$ Herbert Wertheim College of Medicine, Florida International University, Miami, USA \\ ${ }^{3}$ Neurobehavioral Institute of Miami, Miami, USA \\ Email: jherreramdphd@gmail.com
}

Received 21 February 2014; revised 14 March 2014; accepted 29 March 2014

Copyright (C) 2014 by authors and Scientific Research Publishing Inc.

This work is licensed under the Creative Commons Attribution International License (CC BY).

http://creativecommons.org/licenses/by/4.0/

\section{(c) (i) Open Access}

\section{Abstract}

The Mini-Mental State Examination is perhaps the most frequently used instrument to determine level of cognitive functioning. However, while it is cited in a wide range of research studies, it is not necessarily the focus of study itself. The purpose of this study was to establish the ability of the MMSE total score to predict the level of neurocognitive functioning of two samples of Hispanic patients with minor neurocognitive disorder in a battery of neuropsychological tests. Two samples of patients, one obtained in 2009 and a second one in 2013 were grouped into high scoring and low scoring in the MMSE. The results showed that the MMSE total score was predictive of the performance of both samples in neuropsychological tests designed to assess attention, language, non-verbal memory, and visual-constructional praxis. Scores in an auditory verbal memory task was not predicted by the total score of the MMSE. It was concluded that the MMSE could serve as a very adequate instrument to predict neurocognitive functioning in patients with memory complaints. The consistency of findings between the two independent samples gave further credence to this assertion.

\section{Keywords}

Mini-Mental State Examination, Neuropsychological Evaluation, Minor Neurocognitive Disorder, Mild Cognitive Impairment 


\section{Introduction}

The Mini-Mestal State Examination (MMSE; Folstein, Folstein, \& McHugh, 1975; Folstein et al., 2001, 2002) was proposed by its authors as a relatively quick measure of cognitive functioning. This is especially important for patients whose endurance or perseverance are poor, given their condition. Among these are primarily the elderly and the patients that suffer from symptoms of dementia or cognitive impairment. This instrument was also proposed as a standardized procedure that could be used more than once to assess cognitive decline.

The validity and reliability of the MMSE were initially reported by Fostein, Folstein and McHugh (1975) in two samples of patients with dementia, depression with cognitive impairment, and depression. The value of 20 points as a cutoff score between patients and controls was established on the basis of the examination of 137 patients and 63 healthy controls.

The MMSE is made up of 11 items, which yield a total score of 30 points. The areas of cognitive functioning assessed by this instrument are: orientation, memory, attention, language, and visual constructional praxis.

The MMSE is, perhaps, the instrument of its type of greater utilization in the field of brain-behavior assessment. However, it has not been until recently that frequent bibliographical references about this instrument itself in regards to dementia and other neurological disorders have been introduced. The MMSE is used frequently in a description of the characteristics of participant samples in a wide range of research, but it is not always itself the subject of study. Thus, a review of the literature that mentions the use of the MMSE reveals that the majority of studies are not about the instrument itself.

The use of the MMSE is at present almost universal. The literature shows that it has been used in research conducted in Sweden (Rönnlund et al., 2005; Dickerson et al., 2005), Holland (Spaan, Raaijmakers, \& Jonker, 2005), France (Elbaz et al., 2005; Haubois et al., 2011; Bugnicourt et al., 2013), Argentina (Sarasola et al., 2005), the United States (Daniels et al., 2012; Buckingham et al., 2013), Finland (Alhola et al., 2005; Wikman \& Summala, 2005), Canada (Alagiakrishnan et al., 2013), Italy (Caffarra et al., 2013), Australia (Faux et al., 2010; Cameron et al., 2012), Norway (Fjærtoft et al., 2011), Korea (Kim et al., 2010; Park et al., 2014), Belgium (Adam et al., 2005), Brazil (Alencar et al., 2010), China (Malhotra et al., 2013; Tsemg, et al., 2013) and Japan (Yajima et al., 2013), among others.

The MMSE has been used with a variety of patients suffering from a number of neurological and systemic conditions. Among these are dementias, including Alzheimer's disease (Sarasola et al., 2005; Foldi et al., 2005; Adam et al., 2005; O’Hara et al., 2005; Festa et al., 2005; Lipton et al., 2005; Bartzokis et al., 2006; Khachiyants \& Kim, 2012; Malhotra et al., 2013; Caffarra et al., 2013; Razlighi et al., 2014). Mild cognitive impairment has also been traditionally a condition with which the MMSE has been frequently used (Boyle et al., 2005; Dickerson et al., 2005; Jack et al., 2005; Haubois et al., 2011; Cameron et al., 2012; Alagiakrishnan et al., 2013).

In 2013, with the advent of the fifth edition of the diagnostic and statistical manual of mental disorders (DSM5; American Psychiatric Association, 2013) what had been referred to previously as mild cognitive impairment was raised to the level of a formal diagnosis with the name of minor neurocognitive disorder.

The aim of the present study is to determine the ability of the MMSE to predict neurocognitive functioning in two samples of Hispanic patients who have complained to their primary care physicians of having memory difficulties in a battery of neuropsychological tests.

\section{Methodology}

\subsection{Ethical Considerations}

The study was approved by the Institutional Review Board of the Medical Care Consortium. Inc. (MCCI) as an archival, cross-sectional, quasi-experimental research.

\subsection{Participants}

The study included two independent samples of Hispanic patients that had been referred to the Cognitive Health Program of the Medical Care Consortium, Inc. (MCCI) for neuropsychological evaluation by their primary care physicians for complaining of memory difficulties, and thus, given a diagnosis of minor neurocognitive disorder. These patients were administered a battery of neuropsychological tests, including the MMSE. MCCI is a multicenter health care provider that offers primary and specialized medical services in out-patient settings.

The data for the first group was gathered in 2009. This sample was made up of 100 otherwise healthy patients, 
who were referred consecutively to the Cognitive Health Program of MCCI for neuropsychological evaluation by their primary care physicians for presenting memory complaints.

The 2009 sample was subsequently divided into two other groups, according to the scores obtained in the MMSE. A total of 30 participants were included in the low score group (MMSELS). The mean value of the total score of the MMSE for this group was 19.73, with a standard deviation of 2.57. Another 30 participants were included in the high score group (MMSEHS). The average total score of the MMSE for this group was 28.73, with a standard deviation of 0.73 . A Student-t test of statistical significance showed that the difference between these two means was significant $(p<0.000)$.

The data for the second group was gathered in 2013. This group also consisted of 100 otherwise healthy patients of Hispanic origin that were seen consecutively for the purpose of administering a neuropsychological test battery, as referred by their primary care physicians. They were enrolled in the Cognitive Health Program of MCCI, where they subsequently received cognitive rehabilitation services (Herrera Pino et al., 2013).

The sample of 100 participants was divided into two groups, according to their performance in the MMSE. Of these, 30 participants were assigned to the low score group (MMSELS). The mean total score in the MMSE for this group was 20. 38 (sd = 2.37). A group of 30 participants was designated as the high score sample (MMSEHS). The mean value of the total score in the MMSE of this sample was $28.62(\mathrm{sd}=0.70)$. A Student-t test of statistical significance revealed that these two means differed significantly $(p<0.000)$.

\section{Instruments and Procedures}

All participants in this study, including the 2009 and 2013 samples, were administered the MMSE, together with a battery of neuropsychological instruments configured in a process oriented eclectic paradigm. The neuropsychological instruments included in this battery were the written (SDW); and oral (SDO) administrations of the Symbol Digit Modalities Test (Smith, 1973, 1982, 2002), the Controlled Oral Word Association Test (COW; Lezak, Howieson, \& Loring, 2004; Spreen \& Strauss, 1998), and the Boston Naming Test (BNT; Kaplan, Goodglass, \& Weintraub, 1983, 1996).

In addition to these, the administrations RAI (recall of the list in the first trial), RAV (recall of the list in the fifth trial), and RAD (recall of the list with a 20-minute delay) of the Rey Auditory Verbal Learning Test (Schmidt, 1996), the copy (ROC) and delayed (30 minutes) (ROM) administrations of the Rey Osterrieth Complex Figure Test (Rey, 2003; Meyers \& Meyers, 1995), and the Revised Benton Visual Retention Test (BVR; Benton, 1974, 2002; Sivan, 1992) were also included in the battery of instruments administered to all of the participants of this research study. The neuropsychological tests were administered to all of the participants in this study in Spanish, as this was their preferred language.

\section{Data Analysis}

The differences between the mean values obtained by the MMSELS group and the MMSEHS group in the 2009 and 2013 samples in the different neuropsychological instruments administered to them were analyzed by means of the Student-t statistical procedure for independent means.

\section{Results}

As can be seen in Table 1, the demographics of the 2009 sample showed a significant difference in the mean total scores of the MMSE, as well as in their level of education. No significant difference was found in regards to the mean age value of both groups.

In Table 2, the differences between the mean values obtained by the MMSELS group and the MMSEHS group of the 2009 sample can be seen. The MMSE was able to predict to differences in these means in all of the measures taken, except two of them. In the RAI condition of administration of the Rey Auditory Verbal Learning Test, the patients had to recall as many words as they could from a list of 15 words presented to them aurally. It is interesting to note that both groups, MMSELS and MMSEHS, performed poorly in this task.

In the RAD condition of administration of the same instrument, the scores did not differ significantly either. This task required the patients to recall the list of 15 words that had been presented previously five times after a 20-minute delay. Once again, both groups performed poorly in this task. 
Table 1. Demographics by group (2009) sample.

\begin{tabular}{|c|c|c|c|}
\hline & \multicolumn{3}{|c|}{ Groups by MMSE score } \\
\hline & $\begin{array}{c}\text { MMSELS } \\
\mathrm{N}=30\end{array}$ & $\begin{array}{c}\text { MMSEHS } \\
\mathrm{N}=30\end{array}$ & Student $\mathrm{t}$ \\
\hline MMSE & $\begin{array}{c}19.7333 \\
(2.57218)\end{array}$ & $\begin{array}{c}28.7333 \\
(0.78492)\end{array}$ & $-18.330^{*}$ \\
\hline Age & $\begin{array}{c}74.0667 \\
(5.81279)\end{array}$ & $\begin{array}{c}71.8333 \\
(9.88584)\end{array}$ & 1.067 \\
\hline $\begin{array}{l}\text { Education } \\
\text { (Years) }\end{array}$ & $\begin{array}{c}6.1667 \\
(4.51880)\end{array}$ & $\begin{array}{c}10.0667 \\
(4.54049)\end{array}$ & $-3.335^{* *}$ \\
\hline
\end{tabular}

MMSELS = Mini Mental Status Exam Low Scoring; MMSEHS = Mini Mental Status Exam High Scoring; ( ) Standard Deviation ${ }^{*} p \leq 0.000 ;{ }^{* *} p \leq$ 0.001 .

Table 2. Means and standard deviations in neuropsychological tests by group (2009 sample).

\begin{tabular}{|c|c|c|c|}
\hline \multirow{2}{*}{$\begin{array}{l}\text { NP } \\
\text { Tests }\end{array}$} & \multicolumn{3}{|c|}{ Groups by MMSE Score } \\
\hline & $\begin{array}{c}\text { MMSELS } \\
\mathrm{N}=30\end{array}$ & $\begin{array}{c}\text { MMSEHS } \\
\mathrm{N}=30\end{array}$ & Student $\mathrm{t}$ \\
\hline SDO & $\begin{array}{c}9.9000 \\
(5.43520)\end{array}$ & $\begin{array}{c}26.7000 \\
(9.40708)\end{array}$ & $-8.470^{*}$ \\
\hline SDW & $\begin{array}{c}6.6667 \\
(4.15504)\end{array}$ & $\begin{array}{l}21.8667 \\
(9.73700)\end{array}$ & $-7.864^{*}$ \\
\hline COW & $\begin{array}{c}12.1000 \\
(5.64068)\end{array}$ & $\begin{array}{c}24.7000 \\
(9.05215)\end{array}$ & $-6.471^{*}$ \\
\hline BNT & $\begin{array}{c}14.3667 \\
(4.73056)\end{array}$ & $\begin{array}{c}21.6000 \\
(3.47007)\end{array}$ & $-6.753^{*}$ \\
\hline RAI & $\begin{array}{c}3.3333 \\
(1.02833)\end{array}$ & $\begin{array}{c}4.0000 \\
(1.33907)\end{array}$ & -2.163 \\
\hline RAV & $\begin{array}{c}6.7667 \\
(2.20788)\end{array}$ & $\begin{array}{c}9.5667 \\
(2.59553)\end{array}$ & $-4.501^{*}$ \\
\hline RAD & $\begin{array}{c}3.5333 \\
(2.58288)\end{array}$ & $\begin{array}{c}5.4000 \\
(3.83810)\end{array}$ & -2.210 \\
\hline ROC & $\begin{array}{c}18.6500 \\
(8.69021)\end{array}$ & $\begin{array}{c}28.5833 \\
(5.22937)\end{array}$ & $-5.364^{*}$ \\
\hline ROM & $\begin{array}{c}4.7333 \\
(3.85901)\end{array}$ & $\begin{array}{c}9.4167 \\
(5.06013)\end{array}$ & $-4.031^{*}$ \\
\hline BVR & $\begin{array}{c}1.0333 \\
(1.21721)\end{array}$ & $\begin{array}{c}3.5667 \\
(1.54659)\end{array}$ & $-7.050^{*}$ \\
\hline
\end{tabular}

MMSELS = Mini Mental Status Exam Low Scoring; MMSEHS = Mini Mental Status Exam Low Scoring; SDO = Symbol Digit Modalities Oral; SDW = Symbol Digit Modalities Written; COW = Controlled Oral Word Association; BNT = Boston Naming Test; RAI = Rey Auditory Verbal Learning (I); RAV = Rey Auditory Verbal Learning (V); RAD = Rey Auditory Verbal Learning (D); ROC = Rey Osterrieth Complex Figure Copy; ROM = Rey Osterrieth Complex Figure Memory; BVR = Benton Visual Retention; ( ) Standard Deviation; ${ }^{*} p \leq 0.000$.

Table 3 shows the demographic values for both the MMSELS and the MMSEHS groups in the 2013 sample. Just as it was the case with the 2009 sample, these groups differed significantly in their MMSE mean total scores, as well as in their level of education. However, no significant differences were noted in age.

An inspection of Table 4 reveals that the differences between the mean values obtained by the MMSELS group and the MMSEHS group of the 2013 sample in the different neuropsychological instruments included in the battery administered to all study participants were statistically significant, except for the RAI condition of administration of the Rey Auditory Verbal Learning Test. Once again, the participants of both groups performed poorly in this task.

\section{Discussion}

The results obtained in the present study clearly contribute to lend further credence to the use of the MMSE in the process of assessing the cognitive status of patients with minor neurocognitive disorder. This instrument was 
Table 3. Demographics by group (2013 sample).

\begin{tabular}{cccc}
\hline & & Groups by MMSE Score & \\
& MMSELS & MMSEHS & Student t \\
\cline { 2 - 4 } MMSE & $\mathrm{N}=30$ & $\mathrm{~N}=30$ & $-20.921^{*}$ \\
& 20.382 & 28.625 & -1.975 \\
Age & $(2.3743)$ & $(0.7048)$ & $-5.716^{*}$ \\
Education & 69.56 & 73.40 & $(7.045)$ \\
(years) & $(9.294)$ & 11.450 & $-3.3083)$ \\
\hline
\end{tabular}

MMSELS = Mini Mental Status Exam Low Scoring; MMSEHS = Mini Mental Status Exam High Scoring; ( ) Standard Deviation; ${ }^{*} p \leq 0.000$.

Table 4. Means and standard deviations in neuropsychological tests by group (2013 sample).

\begin{tabular}{|c|c|c|c|}
\hline \multirow{2}{*}{$\begin{array}{l}\text { NP } \\
\text { Tests }\end{array}$} & \multicolumn{3}{|c|}{ Groups by MMSE score } \\
\hline & $\begin{array}{c}\text { MMSELS } \\
\mathrm{N}=30\end{array}$ & $\begin{array}{c}\text { MMSEHS } \\
\mathrm{N}=30\end{array}$ & Student $\mathrm{t}$ \\
\hline SDO & $\begin{array}{c}13.324 \\
(10.2121)\end{array}$ & $\begin{array}{c}30.175 \\
(10.0023)\end{array}$ & $-7.153^{*}$ \\
\hline SDW & $\begin{array}{c}11.588 \\
(9.2249)\end{array}$ & $\begin{array}{c}25.075 \\
(9.3326)\end{array}$ & $-6.228^{*}$ \\
\hline COW & $\begin{array}{c}14.118 \\
(7.5066)\end{array}$ & $\begin{array}{c}25.825 \\
(8.1646)\end{array}$ & $-6.377^{*}$ \\
\hline BNT & $\begin{array}{c}16.618 \\
(3.6847)\end{array}$ & $\begin{array}{c}22.425 \\
(3.6717)\end{array}$ & $-6.770^{*}$ \\
\hline RAI & $\begin{array}{c}3.647 \\
(1.4747)\end{array}$ & $\begin{array}{c}4.200 \\
(1.3625)\end{array}$ & -1.675 \\
\hline RAV & $\begin{array}{c}5.500 \\
(2.2597)\end{array}$ & $\begin{array}{c}7.975 \\
(1.9675)\end{array}$ & $-5.037^{*}$ \\
\hline RAD & $\begin{array}{c}3.765 \\
(2.2571)\end{array}$ & $\begin{array}{c}6.000 \\
(2.3205)\end{array}$ & $-4.182^{*}$ \\
\hline ROC & $\begin{array}{c}21.588 \\
(7.9463)\end{array}$ & $\begin{array}{c}29.713 \\
(5.4619)\end{array}$ & $-5.186^{*}$ \\
\hline ROM & $\begin{array}{c}6.809 \\
(4.4228)\end{array}$ & $\begin{array}{c}10.413 \\
(5.2439)\end{array}$ & $-3.163^{* *}$ \\
\hline BVR & $\begin{array}{c}1.941 \\
(1.7571)\end{array}$ & $\begin{array}{c}3.925 \\
(1.7887)\end{array}$ & $-4.793^{*}$ \\
\hline
\end{tabular}

MMSELS = Mini Mental Status Exam Low Scoring; MMSEHS = Mini Mental Status Exam Low Scoring; SDO = Symbol Digit Modalities Oral; SDW = Symbol Digit Modalities Written; COW = Controlled Oral Word Association; BNT = Boston Naming Test; RAI = Rey Auditory Verbal Learning (I); RAV = Rey Auditory Verbal Learning (V); RAD = Rey Auditory Verbal Learning (D); ROC = Rey Osterrieth Complex Figure Copy; ROM = Rey Osterrieth Complex Figure Memory; BVR = Benton Visual Retention; ( ) Standard Deviation; ${ }^{*} p \leq 0.000 ;{ }^{* *} p \leq 0.002$.

shown to be capable of predicting the performance of patients with minor neurocognitive disorder in a number of different neuropsychological instruments. In addition to this, the present study fulfills one of the most important premises in scientific research. The scientific method is based on the notion that it facilitates the replication of previous findings, in order to make knowledge stronger. Two totally independent samples of patients were used in this investigation, one sample studied in 2009 and a second sample in 2013.

An inspection of the results obtained by both samples, not only in the MMSE, but also in the neuropsychological instruments included in the battery used in the assessment of all participants, reveals more than acceptable level of consistency. In both samples, the MMSE was able to predict the performance of the participants of the study in a variety of higher cerebral functions assessed by the different instruments included in the battery used. This included the attentional and incidental memory processes assessed by both conditions of administration, oral and written, of the Symbol Digit Modalities Test, as well as the working memory and sustained attention abilities assessed by the Revised Benton Visual Retention Test.

The MMSE was also shown to be capable to predict in both samples of patients the language skills assessed 
by the Controlled Oral Word Association Test, as well as the naming function of language assessed by the Boston Naming Test. Visual constructional praxis and incidental visual memory assessed by the Rey Osterrieth Complex Figure Test were also among the higher cerebral functions predicted by the scores in the MMSE.

In the 2009 sample, the MMSE was not predictive of the auditory verbal learning memory functions assessed by the RAI and RAD conditions of administration of the Rey Auditory Verbal Learning Test, nor was it predictive of the values obtained in the RAI by both MMSELS and MMSRHS groups in the 2013 sample. A plausible explanation of these findings is that the patients included in this study may well have suffered from what, until 2013, was referred to as amnestic mild cognitive impairment.

\section{Conclusions and Recommendations}

The findings of this study support the use of the MMSE in the assessment process of patients with what has been previously known as mild cognitive impairment, and currently referred to as minor neurocognitive disorder. It should be noted, however, that any screening instrument, such as the MMSE runs the risk of producing a false negative finding. In the case of the MMSE, in particular, the literature shows that normative samples usually have a very tight distribution, reflected in very small values for the standard deviation. On the other hand, pathological samples have traditionally shown a much greater dispersion, as reflected in higher values for the standard deviation (Herrera Pino et al., 2007).

This is exactly the case of the scores obtained in the MMSE by both the 2009 and 2013 samples assessed in this study. In the 2009 sample, the mean value of the total score of the MMSE for the high-scoring group was 28.73, with a standard deviation of 0.78 . The mean value in a total score of the MMSE for the high-scoring group in the 2013 sample was 28.62, with a standard deviation of 0.70 . The standard deviation as a measure of dispersion did not even reach a value of one point in either of the samples.

In contrast to this, the mean MMSE total score for the low-scoring group of the 2009 sample was 19.73, with a corresponding standard deviation of 2.57. The mean MMSE total score value for the low-scoring group of the 2013 sample was 20.38, and the standard deviation was 2.37. It is interesting to note that in the review of the literature pertaining to the MMSE conducted by Herrera Pino et al. (2007), this type of finding was consistent across studies conducted even in different countries.

These findings mean that, whereas, the more cognitively intact samples do not vary greatly from their measure of central tendency, pathological or clinical samples may include individuals that even though they may have a relatively high score in the MMSE, they may still suffer from a significant degree of cognitive impairment, or even conditions such as dementia. A positive finding in the MMSE may well be taken as a solid basis for formulating diagnostic impression, but a negative finding needs to be further validated by the use of a more formal assessment procedure, such as a neuropsychological evaluation.

It is also recommended that the study be conducted with community living elderly individuals without any cognitive impairment or neurological condition. This will allow a better generalization of results to the population at large.

\section{References}

Adam, S., Van der Linden, M., Collette, F., Lemauvais, L., \& Salmon, E. (2005). Further Exploration of Controlled and Automatic Memory Processes in Early Alzheimer's Disease. Neuropsychology, 19, 420-427. http://dx.doi.org/10.1037/0894-4105.19.4.420

Alagiakrishnan, K., Zhao, N., Mereu, L., Senior, P., \& Senthilselvan, A. (2013). Montreal Cognitive Assessment Is Superior to Standardized Mini-Mental Status Exam in Detecting Mild Cognitive Impairment in the Middle-Aged and Elderly Patients with Type 2 Diabetes Mellitus. BioMedical Research International, 2013, 1-5. http://dx.doi.org/10.1155/2013/186106

Alencar, R. C., Cobas, R. A., \& Gomes, M. B. (2010). Assessment of Cognitive Status in Patients with Type 2 Diabetes through the Mini-Mental Status Examination: A Cross-Sectional Study. Diabetology \& Metabolic Syndrome, 2, 1-6. http://www.dmsjournal.com/content/2/1/10

Alhola, P., Tallus, M., Kïlmälä, M., Portin, R., \& Polo-Kamola, P. (2005). Sleep Deprivation, Cognitive Performance, and Hormone Therapy in Postmenopausal Women. Menopause: The Journal of the North American Menopause Society, 12, 149-155.

American Psychiatric Association (2013). Diagnostic and Statistical Manual of Mental Disorders (5th ed.). Washington DC: 
American Psychiatric Association.

Bartzokis, G., Lu, P. H., Geschwind, D. H., Edwards, N., Mintz, J., \& Cummings, J. L. (2006). Apolipoprotein E Genotype and Age-Related Myelin Breakdown in Healthy Individuals: Implications for Cognitive Decline and Dementia. Archives of General Psychiatry, 63, 63-72. http://dx.doi.org/10.1001/archpsyc.63.1.63

Benton, A. L. (1974). Revised Visual Retention Test (4th ed.). New York: The Psychological Corporation.

Benton, A. L. (2002). Test de Retención Visual de Benton: Manual (5th ed.). Madrid: TEA Ediciones, S.A.

Boyle, P. A., Wilson, R. S., Aggarwal, N. T., Arvanitakis, Z., Kelly, J., Bienias, J. L., \& Bennert, D. A. (2005). Parkinsonian Signs in Subjects with Mild Cognitive Impairment. Neurology, 65, 1901-1908.

http://dx.doi.org/10.1212/01.wnl.0000188878.81385.73

Buckingham, D. N., Mackor, K. M., Miller, R. M., Pullam, N. N., \& Molloy, K. N. (2013). Comparing the Cognitive Screening Tools: MMSE and SLUMS. PURE Insights, 2, Article 3.

Bugnicourt, J. M., Godefroy, O., Chillon, J. M., Choukroun, G., \& Massy, Z. A. (2013). Cognitive Disorders and Dementia in CKD: The Neglected Kidney-Brain Axis. Journal of the American Society of Nephrology, 24, 1-11. http://dx.doi.org/10.1681/ASN.2012050536

Caffarra, P., Gardini, S., Dieci, F., Copelli, S., Maset, L., Concari, L., Farina, L., \& Grossi, E. (2013). The Qualitative Scoring MMSE Pentagon Test (QSPT): A New Method for Differentiating Dementia with Lewy Body from Alzheimer's Disease. Behavioural Neurology, 27, 213-220.

Cameron, J., Worrall-Carter, L., Page, K., Stewart, S., \& Ski, C. F. (2012). Screening for Mild Cognitive Impairment in Patients with Heart Failure: Montreal Cognitive Assessment versus Mini Mental State Exam. European Journal of Cardiovascular Nursing. http://dx.doi.org/10.1177/1474515111435606

Daniels, T. B., Brown, P. D., Felten, S. J., Wu, W., Buckner, J. C., Arusell, R. M., Curran, W. J.. Abrams, R. A., Schiff, D., \& Shaw, E. G. (2011). Validation of EORTC Prognostic Factors for Adults with Lowgrade Glioma: A Report Utilizing Intergroup 86-72-51. International Journal of Radiation Oncology and Biological Physics, 81, 218-224. http://dx.doi.org/10.1016/j.ijrobp.2010.05.003

Dickerson, B. C., Salat, D. H., Greve, D. N., Chua, E. F., Rand-Giovannetti, E., Rentz, D. M., Bertram, L., Mullin, K., Tanzi, R. E., Blacker, D., Albert, M. S., \& Sperling, R. A. (2005). Increased Hippocampal Activation in Mild Cognitive Impairment Compared to Normal Aging and AD. Neurology, 65, 404-411. http://dx.doi.org/10.1212/01.wnl.0000171450.97464.49

Elbaz, A., Ripert, M., Tavernier, B., Février, B., ureik, M., Gariépy, J., Alpérovich, A., \& Tzourio, C. (2005). Common Carotid Artery Intima-Media Thickness, Carotid Plaques, and Walking Speed. Stroke, 36, 2198-2202. http://dx.doi.org/10.1161/01.STR.0000181752.16915.5c

Faux, N. G., Ritchieb, C. W., Gunna, A., Rembacha, A., Tsatsanisa, A., Bedod, J., Harrisone, J., Lannfeltf, L., Blennowg, K., Zetterbergg, H., Ingelssonf, M., Masters, C. I., Tanzih, R. E., Cummings, J. L., Herdjm, C. M., \& Busha, A. I. (2010). PBT2 Rapidly Improves Cognition in Alzheimer's Disease: Additional Phase II Analyses. Journal of Alzheimer's Disease, 20, 509-516.

Festa, E. K., Insler, R. Z., Salmon, D. P., Paxton, J., Hamilton, J. M., \& Heindel, W. C. (2005). Neocortical Desconnectivity Disrupts Sensory Integration en Alzheimer's Disease. Neuropsychology, 19, 728-738. http://dx.doi.org/10.1037/0894-4105.19.6.728

Fjærtoft, H., Rohweder, G., \& Indredavik, B. (2011). Stroke Unit Care Combined with Early Supported Discharge Improves 5-Year Outcome: A Randomized Controlled Trial. Stroke, 42, 1707-1711. http://dx.doi.org/10.1161/STROKEAHA.110.601153

Foldi, N. S., Schaeffer, L. A., White, R. E. C., Johnson, R., Berger, J. P., Carney, M. T., \& Macina, L. O. (2005). Effect of Graded Levels of Physical Similarity and Density on Visual Attention in Patients with Alzheimer's Disease. Neuropsychology, 19, 5-17. http://dx.doi.org/10.1037/0894-4105.19.6.728

Folstein, M. F., Folstein, S. E., \& McHugh, P. R. (1975). "Mini-Mental State”: A Practical Guide for Grading the Cognitive State of Patients for the Clinician. Journal of Psychiatric Research, 12, 189-198.

http://dx.doi.org/10.1016/0022-3956(75)90026-6

Folstein, M. F., Folstein, S. E., McHugh, P. R., \& Fanjiang, G. (2002). MMSE Examen Cognoscitivo Mini-Mental. Madrid: TEA Ediciones, S.A.

Folstein, M. F., Folstein, S. E., McHugh, P. R., \& Fanjiang, G. (2001). Mini-Mental Status Examination. Odessa, FL: Psychological Assessment Resources.

Haubois, G., Annweiler, C., Launay, C., Fantino, B., de Decker, L., Allali, G., \& Beauchet, O. (2011). Development of a Short Form of Mini-Mental State Examination for the Screening of Dementia in Older Adults with a Memory Complaint: A Case Control Study. BMC Geriatrics, 11, 59-64. http://www.biomedcentral.com/1471-2318/11/59 
http://dx.doi.org/10.1186/1471-2318-11-59

Herrera Pino, J. A., Armas, J., Dieguez, N., \& Alarcon, E. (2013). Conceptual Foundations of a Cognitive Health Program for Hispanic Patients with Minor Neurocognitive Disorder. Psychology, 4, $23-28$. http://dx.doi.org/10.4236/psych.2013.410A005

Herrera, J. A., \& Vargas, J. L. (2007). Handbook of Neuropsychological Examination of Dementia. Coral Gables, FL: Interamerican Academy of Applied Cognitive Neuroscience.

Jack, C. R., Shiung, M. M., Weigand, S. D., O’Brien, P. C., Gunter, J. L., Boeve, B. F., Knopman, D. S., Smith, G. E., Ivnik, R. J., Tangalos, E. G., \& Petersen, R. C. (2005). Brain Atrophy Rates Predict Subsequent Clinical Conversion in Normal Elderly and Amnestic MCI. Neurology, 65, 1227-1231. http://dx.doi.org/10.1212/01.wnl.0000180958.22678.91

Kaplan, E. F., Goodglass, H., \& Weintraub, S. (1983). The Boston Naming Test (2nd ed.). Philadelphia, PA: Lea \& Febiger.

Kaplan, E. F., Goodglass, H., \& Weintraub, S. (1996). Test de Vocabulario de Boston (2da. ed.). Buenos Aires: Editorial Médica Panamericana.

Khachiyants, N., \& Kim, L. (2012). Mini-Mental Status Examination Mapping to the Corresponding Brain Areas in Dementia. ATI-Applied Technologies \& Innovations, 7, 55-58. http://www.academicpublishingplatforms.com

Kim, T. H., Jhoo, J. H., Park, H. J., Kim, J. L., Ryu, S. H., Moon, S. W., Choo, H., Lee, D. W., Yoon, J. C., Do, Y. J., Lee, S. B., Kim, M. D., \& Kim, K. W. (2010). Korean Version of Mini Mental Status Examination for Dementia Screening and Its Short Form. Psychiatry Investigation, 7, 102-108. http://dx.doi.org/10.4306/pi.2010.7.2.102

Lezak, M. D., Howieson, D. D., \& Loring, D. W. (2004). Neuropsychological Assessment (4th ed.). New York, NY: Oxford University Press.

Lipton, A. M., Ohman, K. A., Womack, K. B., Hynan, L. S., Ninman, E. T., \& Lacritz, L. H. (2005). Subscores of the FAB Differentiate Frontotemporal Lobar Degeneration from AD. Neurology, 65, 726-731. http://dx.doi.org/10.1212/01.wnl.0000174437.73416.7b

Malhotra, C., Chan, A., Matchar, D., Seow, D., Chuo, A., \& Do, Y. K. (2013). Diagnostic Performance of Short Portable Mental Status Questionnaire for Screening Dementia among Patients Attending Cognitive Assessment Clinics in Singapore. Annals of the Academy of Medicine Singapore, 42, 15-19.

Meyers, J. E., \& Meyers, K. R. (1995). Rey Complex Figure Test and Recognition Trial. Odessa, FL: Psychological Assessment Resources.

O’Hara, R., Schroeder, C. M., Kraemer, H. C., Kryla, N., Cao, C., Miller, E., Schatzberg, A. F., Yesavage, J. A., \& Murphy, G. M. (2005). Nocturnal Sleep Apnea/Hypopnea Is Associated with Lower Memory Performance in APOE $\varepsilon 4$ Carriers. Neurology, 65, 642-644. http://dx.doi.org/10.1212/01.wnl.0000173055.75950.bf

Park, B., Jun, J. K., \& Park, J. (2014). Cognitive Impairment and Depression in the Early 60s: Which Is More Problematic in Terms of Instrumental Activities of Daily Living? Geriatrics \& Gerontology International, 14, 62-70. http://dx.doi.org/10.1111/ggi.12055

Razlighi, Q. R., Stallard, E., Brandt, J., Blacker, D., Albert, M., Scarmeas, N., Kinosian, B., Yashin, A. I., \& Stern, J. (2014). A New Algorithm for Predicting Time to Disease Endpoints in Alzheimer's Patients. Journal of Alzheimer's Disease, 38, $1-14$.

Rey, A. (2003). Test de Copia y Reproducción de Memoria de Figuras Complejas (8th ed.). Madrid: TEA Ediciones, S.A.

Rönnlund, M., Nyberg, L., Bäckman, L., \& Nilsson, L. (2005). Stability, Growth, and Decline in Adult Life Span Development of Declarative Memory: Cross-Sectional and Longitudinal Data from a Population-Based Study. Psychology and Aging, 20, 3-18. http://dx.doi.org/10.1037/0882-7974.20.1.3

Sarasola, D., de Luján-Calcagno, M., Sabe, L., Crivelli, L., Torralba, T., Roca, M., García-Caballero, A., \& Manes, F. (2005). El Addenbrooke's Cognitive Examination en español para el diagnóstico de demencia y para la diferenciación entre enfermedad de Alzheimer y demencia frontotemporal. Revista de Neurología, 41, 717-721.

Schmidt, M. (1996). Rey Auditory Verbal Learning Test: A handbook. Los Angeles, CA: Western Psychological Services.

Sivan, A. B. (1992). Benton Visual Retention Test (5th ed.). San Antonio, TX: The Psychological Corporation.

Smith, A. (1973). Symbol Digit Modalities Test. Los Angeles, CA: Western Psychological Services.

Smith, A. (1982). Symbol Digit Modalities Test. Los Angeles, CA: Western Psychological Services.

Smith, A. (2002). SDMT: Test de Símbolos y Dígitos. Madrid: TEA Ediciones, S.A.

Spaan, P. E. J., Raaijmakers, J. G. W., \& Jonker, C. (2005). Early Assessment of Dementia: The Contribution of Different Memory Components. Neuropsychology, 19, 629-640. http://dx.doi.org/10.1037/0894-4105.19.5.629

Spreen, O., \& Strauss, E. (1998). A Compendium of Neuropsychological Tests (2nd ed.). New York, NY: Oxford University Press.

Wikman, A., \& Summala, S. (2005) Aging and Time-Sharing in Highway Driving. Optometry and Vision Science, 82, 716- 
723.

Yajima, K., Matsushita, T., Sumitomo, H., Sakurai, H., Katayama, T., Kanno, K., Sakai, M., Shigeta, M., Shirabe, S., Nakano, T., Nishimura, K., Ueki, A., \& Kitaoka, M. (2013). One-Minute Mental Status Examination for Category Fluency Is More Useful than Mini-Mental State Examination to Evaluate the Reliability of Insulin Self-Injection in Elderly Diabetic Patients Receiving Insulin Therapy. Journal of Diabetes Investigation. http://dx.doi.org/10.1111/jdi.12159 